\title{
The Use of Soy Flour in Yellow Maize-Amaranth Gluten-free Bread Production
}

\author{
Laila Vilmane*, Evita Straumite \\ Department of Food Technology, LLU, Liela iela 2, Jelgava LV-3001, Latvia
}

\begin{abstract}
Celiac disease is a permanent enteropathy caused by the ingestion of gluten, a protein occurring in wheat, rye, and barley. Gluten-free products often have a shorter shelf life, lower quality, and not so pronounced flavour. Therefore, it is necessary to develop new gluten-free products with higher quality and pronounced taste. The aim of this study was to investigate the influence of soy flour on the yellow maize-amaranth dough rheological properties and bread quality. To determine the influence of soy flour on gluten-free dough rheological properties and bread quality, soy flour was added at $45 \%, 50 \%$ and $60 \%$ to yellow maize flour basis. To study the effect of the amount of water used in the recipe on dough rheological properties and bread quality, each sample $(n=7)$ was prepared in two versions: one with the dough yield 196, and the other with the dough yield 252. The main quality parameters of dough and bread were determined using the following methods: the firmness and resilience of dough, as well as the hardness of bread slice with a TA.XT.plus Texture Analyser; moisture content of dough - with a thermostat; moisture content of bread crumb - with a Precisa XM 120 at the temperature of $110^{\circ} \mathrm{C}$; and color of bread crumb - in the CIE $\mathrm{L}^{*} \mathrm{a} * \mathrm{~b} *$ color system using a ColorTec-PCM/PSM. The best results of dough rheological properties were obtained for samples with dough yield 196, but the best quality of bread - for samples with dough yield 252. It was proved that soy flour improves not only the dough firmness and resilience but also the volume, texture, hardness, moisture content and color of gluten-free bread. No significant differences in the influence of soy flour on dough rheological properties and bread quality were found between the samples with various added amounts of soy flour $(45 \%, 50 \%$, or $60 \%)$.
\end{abstract}

Key words: Gluten-free bread, color, rheology, soy flour, dough.

\section{Introduction}

Gluten-free products exclude all ingredients containing the proteins of wheat, barley, rye, spelt, and kamut. The term gluten-free does not refer to the total absence of gluten. In the definition of gluten-free, some residual amount of gluten is allowed; this amount is strictly regulated by the Codex Alimentarius Standard. The EU Commission Regulation No. 41/2009 recommends that products not exceeding $20 \mathrm{mg} \mathrm{kg}^{-1}$ of gluten should be considered gluten-free. In recent years, there is an increased interest in gluten-free products as the number of patients with celiac disease is growing (affecting about $1 \%$ of the general population) (Demirkesen, Mert, Sumnu, \& Sahin, 2010a).

Celiac disease is the result from an immune response to ingested dietary gluten in genetically susceptible individuals. The ingestion of gluten and its related peptides leads to malabsorption in the small intestine. The only way to overcome this problem is a lifelong adherence to a strict gluten-free diet (Catassi \& Fasano, 2008; Heap \& van Heel, 2009).

Gluten, found in the endosperm of cereals, is composed of distinct portions of monomeric, alcohol-soluble gliadins and polymeric, prolamine-rich glutenins, which are responsible for flour processing characteristics (good water absorption capacity, cohesiveness, viscosity, and elastic properties) in bakery industry (Arendt \& Nunes, 2010; Heap \& van Heel, 2009; Torbica, Hadnadev, \& Dapčevic, 2010). The development of gluten-free bread with good quality and high nutritional value is a complicated and challenging task to both the cereal technologists and the bakers, because the lack of gluten proteins in gluten-free cereals makes it very difficult to obtain an acceptable yeast-leavened product such as bread, resulting from the absence of a proper network necessary to hold the carbon dioxide produced during proofing. Therefore, many researchers

\footnotetext{
* Corresponding author's email: lailaozola@inbox.lv
} 
have investigated the substitution of gluten by ingredients able to mimic its functional properties (Blanco, Ronda, Perezs, \& Pando, 2011; Torbica, Hadnadev, \& Dapčevic, 2010).

The majority of commercially available gluten-free breads are inferior in quality, which results from the absence of gluten, compared to their gluten-containing counterparts. The major defects in the basic gluten-free bread are that they often present poor quality with a crumbling texture, a dry and friable crumb (crumb that is wet after baking and sticks together, next day becomes dry, rough and crumbly), lack of flavor and mouth feel, poor color, a relatively short shelf life, and other post-baking defects. Also, gluten-free breads are often characterized by a low nutritional quality as they are mainly starch-based and contain low amounts of vitamins, minerals, and in particular dietary fiber (Phimolsiripol, Mukprasirt, \& Schoenlechner, 2012; Torbica, Hadnadev, \& Dapčevic, 2010).

In the last decade, various technological parameters and formulations have been investigated to improve the quality of gluten-free bread by using flour mixtures (Alvarez-Jubete, Auty, \& Arendt, 2010; Lopez, Pereira, \& Junqueira, 2004; Sciarini, Ribotta, Leon, \& Perez, 2010; Torbica, Hadnadev, \& Dapčevic, 2010) or starches (Abdel-Aal, 2009; Milde, Ramallo, \& Puppo, 2012; Onyango, Mutungi, Unbehend, \& Lindhauer, 2011; Ziobro, Korus, Witczak, \& Juszczak, 2012), or sourdough (Gobbetti, Rizzello, Di Cagno, \& De Angelis, 2007) or by adding additives such as hydrocolloids xanthan, psyllium, guar gums, etc. (Anton \& Artfield, 2008; Demirkesen, Mert, Sumnu, \& Sahin, 2010a; Lazaridou, Duta, Papageorgiou, Belc, \& Biliaderis, 2007; Peressini, Pin, \& Sensidoni, 2011), emulsifier (Demirkesen, Mert, Sumnu, \& Sahin, 2010a, 2010b), enzymes (Marco \& Rosell, 2008; Renzetti, Dal Bello, \& Arendt, 2008) or non-gluten proteins such as egg, milk or soybean protein or protein isolates (Crockett, Ie, \& Vodovotz, 2011; Gallagher, Gormley, \& Arendt, 2003; Marco \& Rosell, 2008).

There are two approaches to improve the quality of gluten-free bread by using proteins. One is to use raw materials with a high protein content, and the second one is to add protein isolates to flour. Most popular proteins that are used in a gluten-free bread formulation are eggs and soybean. Eggs are conventional bread additives, which can replace many of the functions that gluten provides, such as binding, enhancing texture and helping set the structure of the final product. Eggs improve color, enhance flavor and are the source of liquid. Easily digested proteins found in eggs are ideal for recovering celiac disease patients (Crockett, Ie, \& Vodovotz, 2011). Soybeans are a good source of protein, saturated fat, and calcium and are high in fiber. Up to $50 \%$ of soy flour composition are proteins that lack gluten, because soybean is a leguminous plant. Due to a lack of a structural protein complex that interferes with gluten development, soy flour produces a dense product with small air cells and is less likely to form tunnels. In addition, the hydrophilic action of soy flour may inhibit gluten development; therefore, soy flour should be mixed with other types of flour to reach result - an acceptable volume and structure of bread (Sim \& Tam, 2001). Soybean proteins and soybean flour have often been used for fortification of bakery products and to improve the protein quality, mechanical behavior and storage life of bakery products (Curic, Novotni, Tusak, Bauman, \& Gabric, 2007).

Additions of soy flour to bread improve the quality of bread. Adding $3-12 \%$ of soy flour increases the dough water absorption and improves product elasticity, crust and color, which is the effect of $\beta$-carotene - a fat-soluble vitamin found in soybean. Tests have shown that the product acquires high flexibility, better color of crumb, and desired crust when the addition of soybeans makes $7 \%$. High concentrations of soy flour also decrease the bread volume, while humidity increases with the increase in the amount of soy flour (Sana, Xhabiri, Seferi, \& Sinani, 2012).

Characteristics of the gluten-free product market situation make it necessary to improve and develop new methods and recipes of gluten-free product preparation. The aim of the present study was to investigate the influence of soy flour on the yellow maize-amaranth dough rheological properties and bread quality.

\section{Materials and Methods}

The experiments were carried out in the laboratories of the Faculty of Food Technology of the Latvia University of Agriculture.

\section{Ingredients}

Yellow maize flour (JSC Ustukiu Malunas, Lithuania), amaranth seed and soybean (Rapunzel, Germany), heat-treated oat flour (Skåne-möllan $A B$, 
Sweden), dry yeast (Saf-instant, France), sugar, salt, apple vinegar, eggs, and vegetable oil from the local market were the materials used in the study. Amaranth seed and soybean were ground in the laboratory mill Hawos (Kornmühlen GmbH, Germany), and the fine flour obtained was used for the experiments.

The general technological scheme for gluten-free bread making is presented in Fig. 1. All ingredients were mixed for $10 \pm 3 \mathrm{~min}$ at a minimum speed using a dough mixer BEAR Varimixer (Wodschow \& Co, Denmark). Dough samples were taken for experiments instantly after mixing. The portions of dough, $275 \mathrm{~g}$ each, were pressed into greased stainless rectangular moulds $(7 \times 14 \times 7 \mathrm{~cm})$ and fermented for $25 \pm 3 \mathrm{~min}$ at $37 \pm 2{ }^{\circ} \mathrm{C}$. Bread samples were baked at $200 \pm 5{ }^{\circ} \mathrm{C}$ for $25 \pm 3 \mathrm{~min}$ in a rotating convection oven (Sveba Dahlen, Sweeden) and then cooled at the room temperature $\left(22 \pm 2{ }^{\circ} \mathrm{C}\right)$ for $40 \pm 5 \mathrm{~min}$.

\section{Samples}

To determine the influence of soy flour on gluten-free dough rheological properties and on bread quality, soy flour was added at $45 \%, 50 \%$ and $60 \%$ to yellow maize flour basis. Also, to study the effect of the amount of water used in the recipe on gluten-free dough rheological properties and bread quality, each sample was prepared in two versions: one with dough yield 196, and the other with dough yield 252. The proportion between flour and water is called the dough yield (DY) and is defined as:

$$
\mathrm{DY}=\frac{\text { (amount of flour }+ \text { amount of water }) \times 100}{\text { amount of flour }}
$$

This means that wheat dough with DY 160 (a lower DY value) is a firm dough and wheat dough with DY 200 (a higher DY value) is a liquid dough (Decock \& Cappelle, 2005).

Seven dough and bread samples were prepared. In this article, the following abbreviations of the samples are used:

- C (control) - sample without soy flour;

- S4DY1 - sample with 45\% of soy flour; DY 196;

- S5DY1 - sample with 50\% of soy flour; DY 196;

- S6DY1 - sample with 60\% of soy flour; DY 196;

- S4DY2 - sample with $45 \%$ of soy flour; DY 252;

- S5DY2 - sample with 50\% of soy flour; DY 252;

- S6DY2 - sample with $60 \%$ of soy flour; DY 252 .

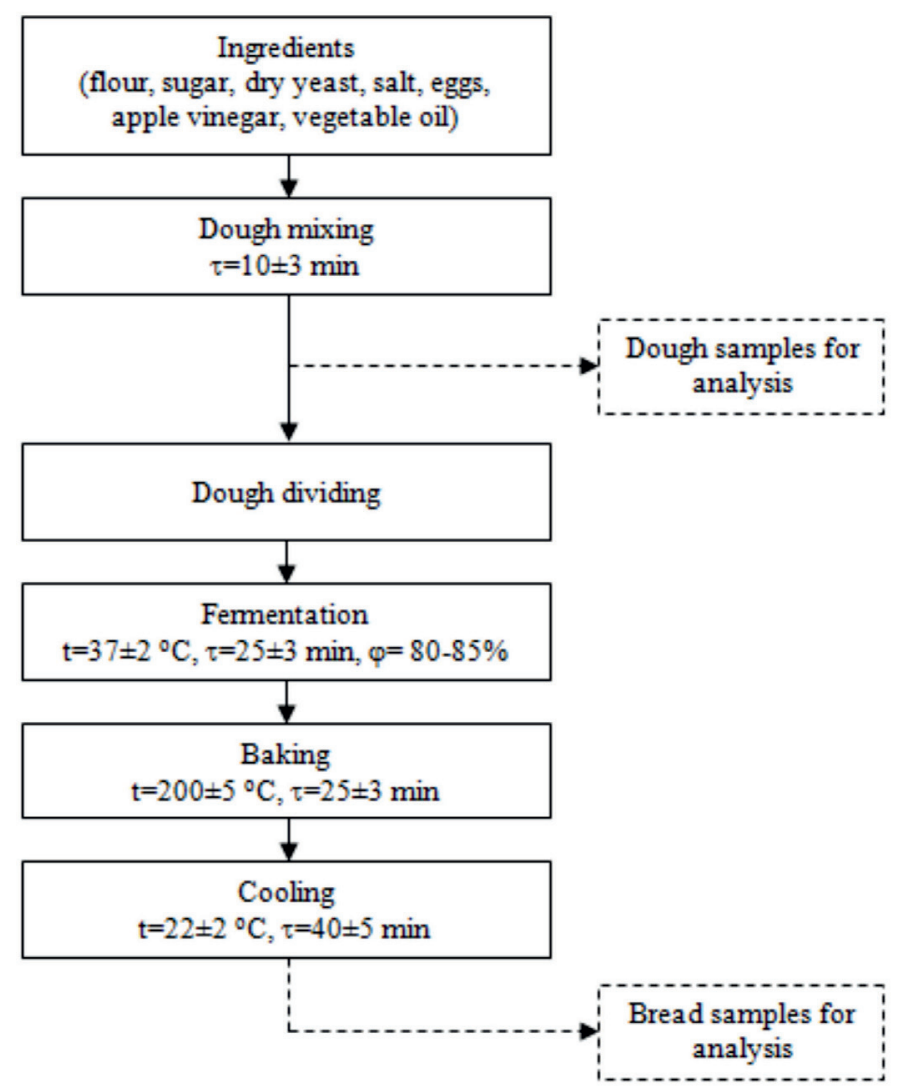

Fig. 1. The general technological scheme of gluten-free bread making. 


\section{Structure analysis}

The firmness and resilience of dough was measured using a TA.XT.plus Texture Analyser (Stable Micro Systems, United Kingdom) with following compression test parameters: HDP/SR; spreadability rig; test speed $-1 \mathrm{~mm} \mathrm{~s}^{-1}$; and distance $-20 \mathrm{~mm}$.

The hardness of bread slice $(60 \times 80 \times 10 \mathrm{~mm})$ samples was measured using a TA.XT.plus Texture Analyser (Stable Micro Systems, United Kingdom) with following compression test parameters: the probe - a $25-\mathrm{mm}$ diameter aluminium cylinder; test speed $-1 \mathrm{~mm} \mathrm{~s}^{-1}$; and distance $-10 \mathrm{~mm}$.

\section{Moisture content}

The moisture content of dough was determined by the oven-dry method using a thermostat in two replications: A 3.1-g sample of dough was dried for four hours at the temperature of $110 \pm 1{ }^{\circ} \mathrm{C}$ (Czuchajowska, Pomeranz, \& Jetters, 1988).

The moisture content of bread crumb was analyzed by the oven-dry method with a Precisa XM 120 (Precisa Gravimetrics AG, Switzerland) at the temperature of $110 \pm 1^{\circ} \mathrm{C}$ in three replications.

\section{Color analysis}

The instrumental measurement of the crumb color of bread slices $(60 \times 80 \times 10 \mathrm{~mm})$ was done in the CIE $\mathrm{L}^{*} \mathrm{a} * \mathrm{~b}^{*} \quad\left(\mathrm{~L} * 0=\right.$ black, $100=$ white, $\mathrm{a}^{*}+$ value $=$ red, -value $=$ green, $\quad b^{*}+$ value $=$ yellow,$\quad-$ value $=$ blue [Phimolsiripol, Mukprasirt, \& Schoenlechner, 2012]) color system using a ColorTec-PCM/PSM (Accuracy Inc., USA). Crumb color measurements were made by placing the samples directly under the colorimeter. The color was measured at five different points within the crumb region, and mean values were reported for each type of the product. The total color difference $(\Delta \mathrm{E})$ was defined by the Minolta equations (2):

$$
\begin{gathered}
\Delta L=\left(L-L_{0}\right), \Delta a=\left(a-a_{0}\right), \Delta b=\left(b-b_{0}\right), \\
\Delta E=\sqrt{\Delta L^{2}+\Delta a^{2}+\Delta b^{2}},
\end{gathered}
$$

where

$\mathrm{L}$, a, and $\mathrm{b}$ - the measured values of bread samples (bread samples with soy flour addition);

$\mathrm{L}_{0}, \mathrm{a}_{0}$, and $\mathrm{b}_{0}$ - the values of the bread without soy flour (control).

The reference values for calculating $\Delta \mathrm{E}$ were the color difference between the control (bread without soy flour) and each bread sample. The values used to determine whether the total color difference is appreciable by the human eye were the following:
- $\Delta \mathrm{E}<1-$ color difference is not obvious for the human eye;

- $\quad 1<\Delta \mathrm{E}<3-$ color difference is not appreciative by the human eye;

- $\Delta \mathrm{E}>3$ - color difference is obvious for the human eye (Sanz, Salvador, Baixauli, \& Fiszman, 2009).

All bread measurements were carried out on the next day, at least $24 \mathrm{~h}$ after bread preparation. The mean and standard deviations and $p$ value were processed by mathematical and statistical methods. The data were subjected to one way analysis of variance (ANOVA). Significance was defined at $p<0.05$.

\section{Results and Discussion}

Three types of gluten-free bread were made in the first stage of the experiment. As control and base, yellow maize bread with extruded maize flour developed in the previous experiments (Ozola, Straumite, Galoburda, \& Klava, 2012; Ozola, Straumite, \& Klava, 2011) was used. In one type of gluten-free bread, extruded maize flour was replaced with heat-treated oat flour; in the other, $38 \%$ of yellow maize flour was replaced with amaranth flour. Both bread samples (maize bread with heat-treated oat flour, and maize bread with amaranth flour) had good quality - similar to the control. In order to improve the quality of bread, it was decided to remove the rice flour from the flour blend used in the previous experiments (Ozola, Straumite, Galoburda, \& Klava, 2012; Ozola, Straumite, \& Klava, 2011) and replace it with amaranth flour.

Many studies have investigated the application of amaranth in the production of nutrient-rich glutenfree products (Alvarez-Jubete, Auty, \& Arendt, 2010; Ballabio et al., 2011; Mariotti, Lucisano, Pagani, \& $\mathrm{Ng}$, 2009). Currently, sources of alternative proteins such as soy flour are used to increase dough elasticity and to improve loaf volume and texture in gluten-free bread (Crockett, Ie, \& Vodovotz, 2011; Gallagher, Gormley, \& Arendt, 2004).

At the beginning of the experiments, to determine the influence of soy flour on gluten-free dough rheological properties and on bread quality, different amounts of soy flour (from 5 to $75 \%$ of the total amount of yellow maize flour) were added to each bread sample. The results showed that the optimal ratio of soy flour addition was $45 \%, 50 \%$, and $60 \%$. In order to achieve the dough consistency suitable for breadmaking, the gluten-free dough requires a higher water absorption than that of the wheat flour. The gluten-free dough has batter-like consistency; therefore, the addition of large quantities of water 
leads to considerable improvement of the dough behavior during mixing (i.e., higher dough stability) (Blanco, Ronda, Perezs, \& Pando, 2011; Torbica, Hadnadev, \& Dapčevic, 2010). To study the influence of water on dough properties, each dough sample was prepared in two versions: one version with $96 \%$ (DY 196) of water added to the flour basis, which served as the control sample, and the other version with a higher, 152\% (DY 252), water amount. The developed gluten-free dough formulations (Table 1) were used in the present study.

\section{Gluten-free dough analysis}

The resilience and firmness of gluten-free dough illustrated in Figure 2 show that the dough samples with soy flour and DY 196 were firmer than the control dough sample without soy flour (C), namely, dough with $45 \%$ of soy flour (S4DY1) was firmer by $42.23 \%$, dough with $50 \%$ of soy flour (S5DY1) was firmer by $44.99 \%$, and dough with $60 \%$ of soy flour (S6DY1) was firmer by $30.14 \%$. Besides, samples with DY 196 were more elastic than the control. The firmness of gluten-free dough samples

Table 1

Gluten-free bread recipes per $1 \mathrm{~kg}$ of flour

\begin{tabular}{|c|c|c|c|c|c|c|c|}
\hline Ingredients, $\mathrm{g}$ & $\mathrm{C}$ & S4DY1 & S4DY2 & S5DY1 & S5DY2 & S6DY1 & S6DY2 \\
\hline Yellow maize flour & 608 & 334 & 334 & 304 & 304 & 248 & 248 \\
\hline Amaranth flour & 312 & 312 & 312 & 312 & 312 & 312 & 312 \\
\hline Heat-treated oat flour & 80 & 80 & 80 & 80 & 80 & 80 & 80 \\
\hline Soy flour & - & 274 & 274 & 304 & 304 & 360 & 360 \\
\hline Dry yeast & 16 & 16 & 16 & 16 & 16 & 16 & 16 \\
\hline Sugar & 80 & 80 & 80 & 80 & 80 & 80 & 80 \\
\hline Salt & 16 & 16 & 16 & 16 & 16 & 16 & 16 \\
\hline Vegetable oil & 128 & 128 & 128 & 128 & 128 & 128 & 128 \\
\hline Apple vinegar & 20 & 20 & 20 & 20 & 20 & 20 & 20 \\
\hline Eggs & 320 & - & - & - & - & - & - \\
\hline Water & 960 & 960 & 1520 & 960 & 1520 & 960 & 1520 \\
\hline In total & 2541 & 2221 & 2781 & 2221 & 2781 & 2221 & 2781 \\
\hline Dough yield & 196 & 196 & 252 & 196 & 252 & 196 & 252 \\
\hline
\end{tabular}

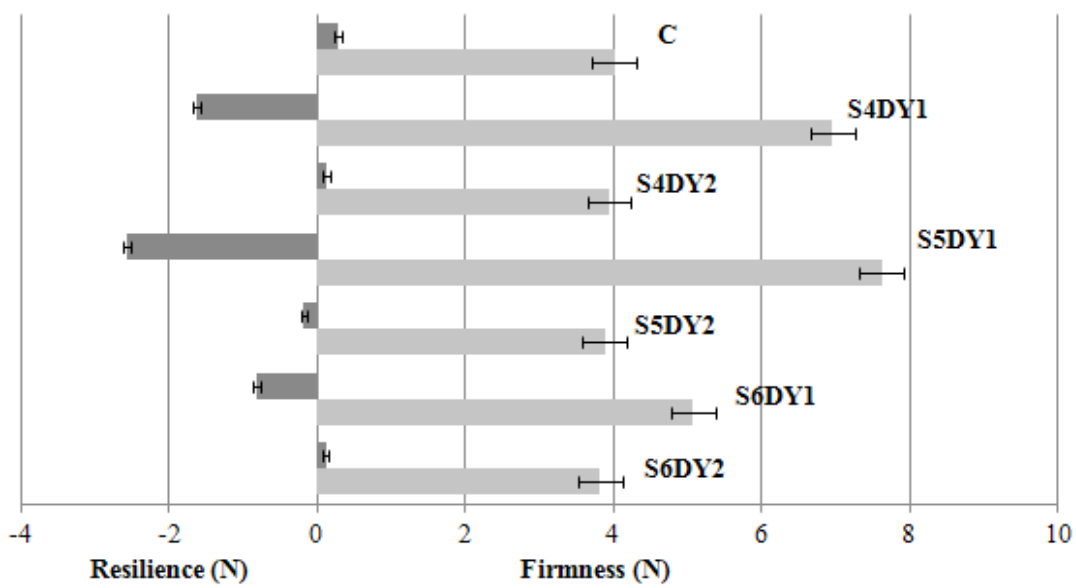

Fig. 2. Resilience and firmness of gluten-free dough:

C - dough without soy flour; S4DY1 - dough with $45 \%$ of soy flour, DY 196 ;

S5DY1 - dough with 50\% of soy flour, DY 196; S6DY1 - dough with 60\% of soy flour, DY 196; S4DY2 - dough with 45\% of soy flour, DY 252; S5DY2 - dough with 50\% of soy flour, DY 252;

S6DY2 - dough with $60 \%$ of soy flour, DY 252. 
with soy flour and DY 252 was similar to that of the control sample. Differences between the control and all analysed samples were not significant $(p>0.05)$ : $0.07 \%$ for sample S4DY2, $0.13 \%$ for sample S5DY2, and $0.19 \%$ for sample S6DY2.

Soy flour in the dough formulations with DY 252 did not significantly $(p>0.05)$ affect the dough resilience, whereas dough samples with soy flour and DY 196 increased the resilience compared to the control: by $83.43 \%$ for sample S4DY1, by $87.94 \%$ for S5DY 1 , and by $76.31 \%$ for S6DY 1 .

The dough samples S4DY1, S5DY1, and S6DY1 exhibited better dough rheological properties than the samples S4DY2, S5DY2, S6DY2, and the control. The data of the dough samples S4DY2, S5DY2, and S6DY2 were similar to those of the control sample. Evidently, the water amount added in the DY 252 recipe formulation was too large to improve the dough rheological properties. Compared to the control, the S4DY1 and S5DY1 samples had better dough rheological properties. The data of S6DY1 are lower than those of S4DY1 and S5DY1 but higher compared to the control, which can be explained by the added amount of soy flour.

The addition of soy flour in the gluten-free dough samples with DY 196 improved the dough rheological properties (i.e., dough firmness and resilience) compared to the control. This can be explained with the amount of water added to dough: The liquid consistency of samples with DY 252 was similar to that of the control sample, but samples with DY 196 had a thicker consistency, which improved the dough rheological properties. Soy flour addition to dough increased water absorption and led to a thicker dough consistency. The study of Sciarini, Ribotta, Leon, and Perez (2010) presents similar data: Soy flour added to a rice-and-maize bread formulation increased the firmness of dough.

The moisture content of gluten-free dough samples is presented in Figure 3. As can be seen, the control sample (C) has a higher moisture content than the dough samples with soy flour: S4DY1 - by 3.53\%, S5DY 1 - by $4.65 \%$, S6DY1 - by $7.68 \%$, S4DY2 by $10.73 \%$, S5DY 2 - by $18.27 \%$, and S6DY2 - by $15.20 \%$. This can be explained by the presence of soy compounds, which absorb comparatively more water, because almost $60 \%$ of soy proteins are soluble in water (Sciarini, Ribotta, Leon, \& Perez, 2010). The moisture content of the dough samples with DY 196 was higher than that of the samples with DY 252.

\section{Gluten-free bread analysis}

The results revealed that compared to the control, the gluten-free bread samples with DY 252 were softer (bread with $45 \%$ of soy flour [S4DY2] - by $25.6 \%$; bread with $50 \%$ of soy flour [S5DY2] - by $20.8 \%$; and bread with $60 \%$ of soy flour [S6DY2] by $44.7 \%$ ), whereas the gluten-free bread samples with soy flour and DY 196 were harder (bread sample S4DY1 - by $88.7 \%$; S5DY1 - by $150.9 \%$; and S6DY1 - 126.8\%) (Fig. 4). To conclude, bread samples with DY 196 were harder than the control and bread samples with DY 252, and dough samples with DY 196 possessed a more pronounced firmness

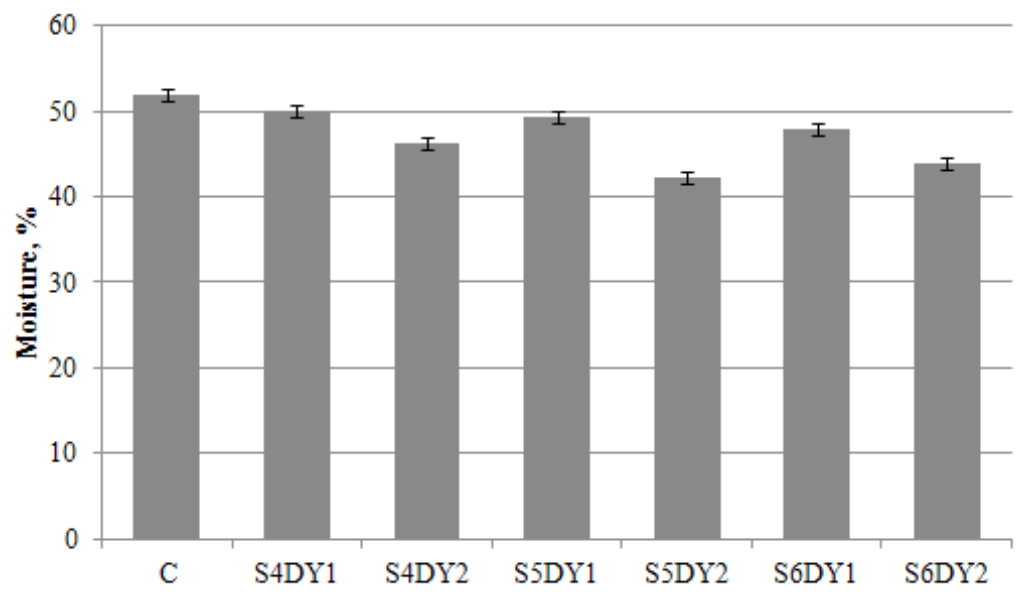

Fig. 3. Moisture content of gluten-free dough samples:

C - dough without soy flour; S4DY1 - dough with 45\% of soy flour, DY 196;

S5DY1 - dough with 50\% of soy flour, DY 196; S6DY1 - dough with $60 \%$ of soy flour, DY 196 ; S4DY2 - dough with $45 \%$ of soy flour, DY 252; S5DY2 - dough with 50\% of soy flour, DY 252;

S6DY2 - dough with $60 \%$ of soy flour, DY 252. 


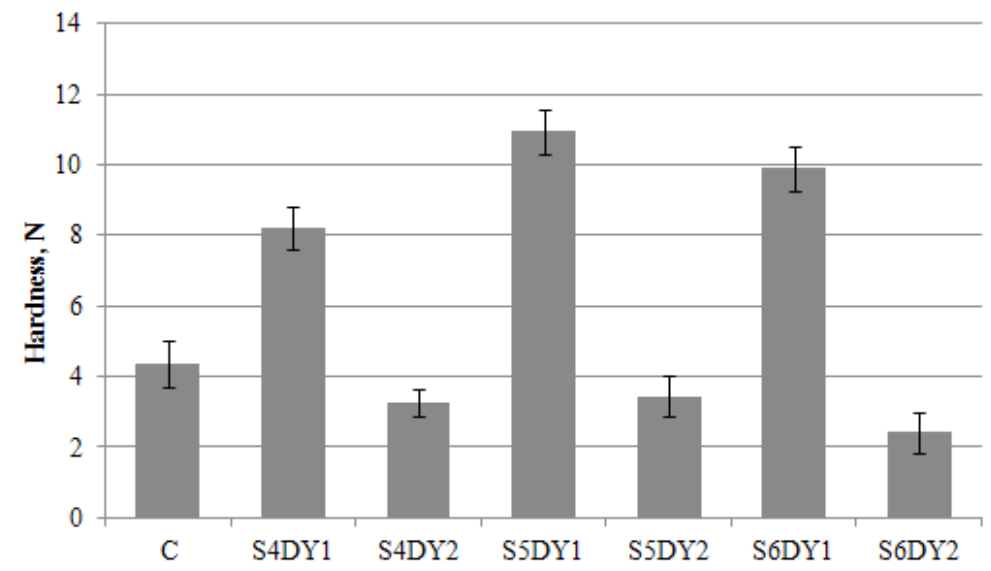

Fig. 4. Crumb hardness of gluten-free bread samples:

C - dough without soy flour; S4DY1 - dough with $45 \%$ of soy flour, DY 196 ;

S5DY1 - dough with 50\% of soy flour, DY 196; S6DY1 - dough with 60\% of soy flour, DY 196; S4DY2 - dough with 45\% of soy flour, DY 252; S5DY2 - dough with 50\% of soy flour, DY 252;

S6DY 2 - dough with $60 \%$ of soy flour, DY 252.
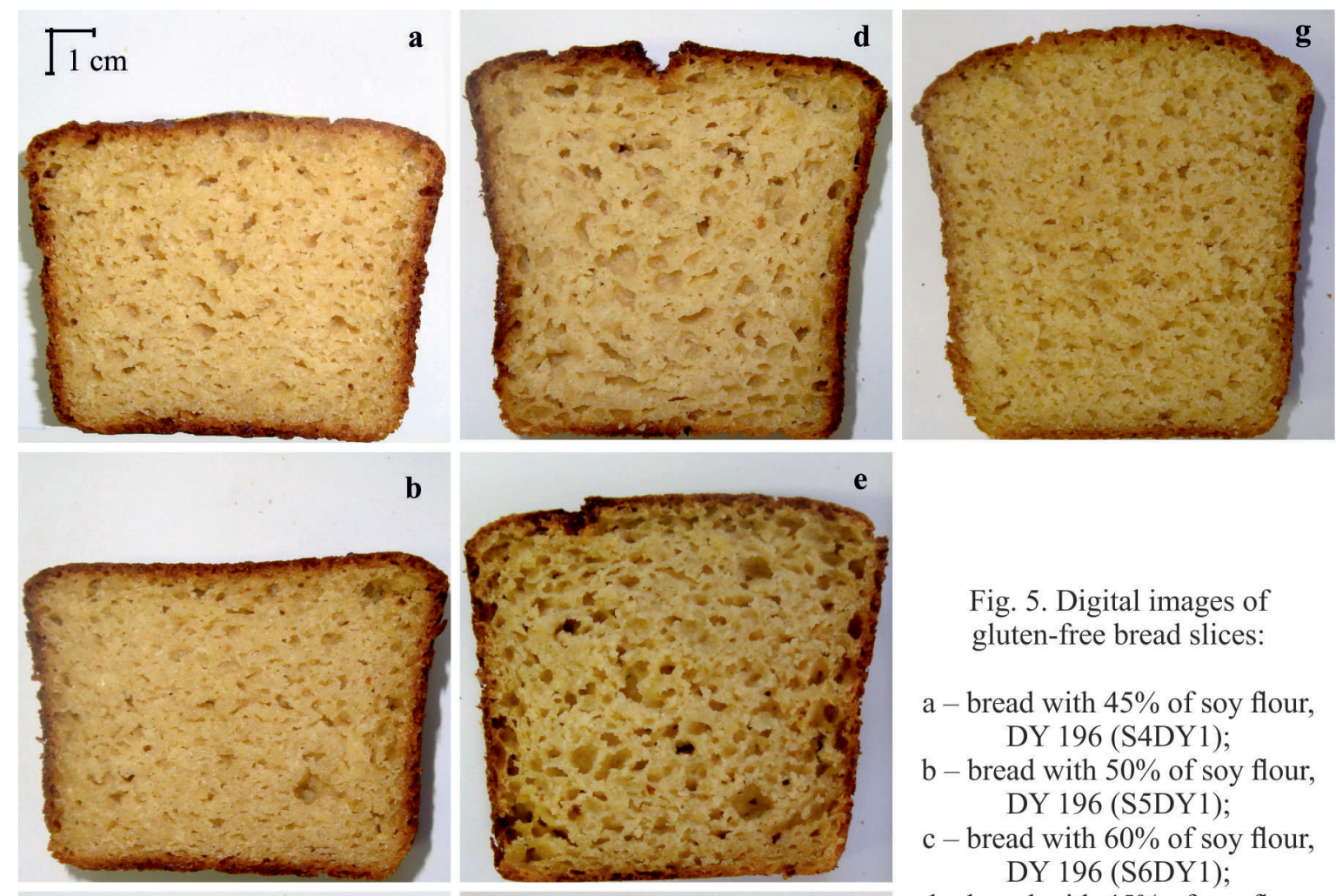

Fig. 5. Digital images of gluten-free bread slices:

a - bread with $45 \%$ of soy flour, DY 196 (S4DY1);

$\mathrm{b}$ - bread with $50 \%$ of soy flour, DY 196 (S5DY1);

c - bread with $60 \%$ of soy flour, DY 196 (S6DY1);
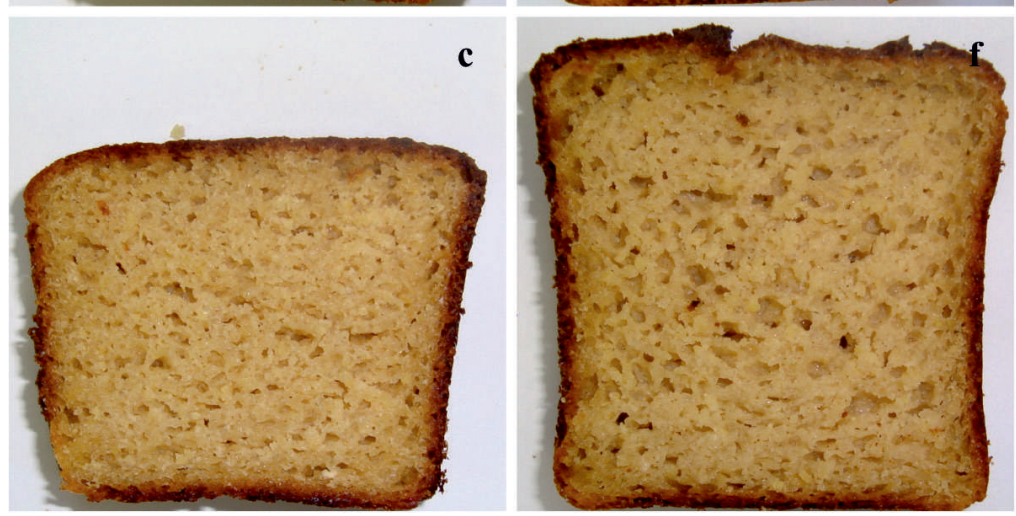

$\mathrm{d}$ - bread with $45 \%$ of soy flour, DY 252 (S4DY2);

e - bread with $50 \%$ of soy flour, DY 252 (S5DY2);

f- bread with $60 \%$ of soy flour, DY 252 (S6DY2);

$\mathrm{g}$ - bread without soy flour (control). 
and resilience than the control and dough samples with DY 252. The research suggests that application of soy flour improved the hardness of bread with DY 252.

An optimally developed dough contains occluded gas cells. The number and size of gas cells, which during baking expand into the open network of pores and determine the crumb structure and volume, are influenced by mixing conditions and flour quality (Oates, 2001). Crumb hardness is related to crumb structure and porosity.

Figure 5 demonstrates the digital images of gluten-free bread slices. The control sample has a good specific volume and a homogeneous pore structure. The pores of the control sample have a similar size and thin walls and are so close to each other that they coalesce in one network (Fig. $5-$ g). The specific volume of the bread sample with $45 \%$ of soy flour and DY 252 (Fig. $5-$ d) is similar to that of the bread sample with $60 \%$ of soy flour and DY 252 (Fig. $5-\mathrm{f}$ ). The pores of the bread samples with DY 252 are large, with irregular structure (Fig. 5-d-f), which contributes to the good specific volume of bread and makes its crumb soft. All bread samples with DY 196 (Fig. 5 - a-c) have irregular shape, small and dense pores, and a smaller specific volume compared both to the control (Fig. $5-\mathrm{g}$ ) and to the bread samples with DY 252 (Fig. 5-d-f).

Compared to the control sample, the moisture content of gluten-free bread samples with soy flour and DY 252 was higher by 3.3\% (S4DY2), 5.9\% (S5DY2), and $4.5 \%$ (S6DY2), whereas that of the bread samples with DY 196 was lower by $13.1 \%$ in the bread sample with $45 \%$ of soy flour (S4DY1), by $7.3 \%$ with $50 \%$ of soy flour (S5DY1), and by $11.9 \%$ with $60 \%$ of soy flour (S6DY1) (Fig. 6). It can be concluded that the amount of soy flour added to dough significantly $(p<0.05)$ affected the moisture content of gluten-free bread.

Color is an important characteristic of baked products and is relevant to their texture and aroma as well as to consumer preference (Esteller \& Lannes, 2008). In Table 2, color values of gluten-free bread indicate that soy flour had a significant effect $(p<0.05)$ on the $\mathrm{L}^{*}$ and $\mathrm{b}^{*}$ values, but not on the $\mathrm{a}^{*}$ values of crumb color. The crumb color of bread samples with soy flour was pale yellow $\left(\mathrm{L}^{*}=61-62\right.$, $\left.a^{*}=-2.05-3.07, b^{*}=29.59-31.56\right)$. Compared to the control, the crumb color of bread samples with soy flour was paler, had lost its yellow shades, and had decreased values of $L^{*}$ (from $63.64 \pm 0.70$ to $61.16 \pm 0.76$ ) and $b^{*}$ (from $34.24 \pm 0.66$ to $29.59 \pm 0.50$ ). The difference in color values of bread crumb can be explained by the added amounts of flour in the gluten-free bread recipes (Table 1): Increased amount of soy flour and decreased amount of yellow maize flour had led to changes in crumb color. All bread samples with soy flour were similar in crumb color and visibly differed from the control sample; therefore, it can be asserted that soy flour affects the color of bread crumb.

Sciarini, Ribotta, Leon, and Perez (2010) assessed the effect of different flours (rice, maize, and soy) and their mixtures on the quality parameters of gluten-free bread. Bread with maize flour had markedly lower

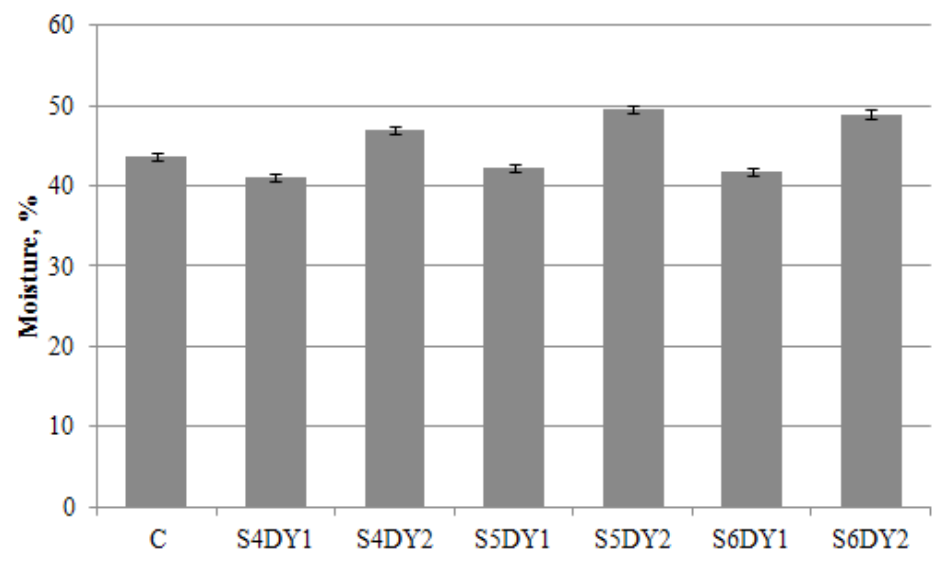

Fig. 6. Moisture content of gluten-free bread:

C - bread without soy flour; S4DY1 - bread with 45\% of soy flour, DY 196;

S5DY1 - bread with $50 \%$ of soy flour, DY 196; S6DY1 - bread with $60 \%$ of soy flour, DY 196 ; S4DY2 - bread with $45 \%$ of soy flour, DY 252 ; S5DY 2 - bread with $50 \%$ of soy flour, DY 252 ;

S6DY2 - bread with $60 \%$ of soy flour, DY 252. 
Gluten-free bread crumb color

\begin{tabular}{ccccc}
\hline \multirow{2}{*}{ Samples } & \multicolumn{3}{c}{ Color value* } & \multirow{2}{*}{$\Delta \mathrm{E}$} \\
\cline { 2 - 4 } & $\mathrm{L}^{*}$ & $\mathrm{a}^{*}$ & $\mathrm{~b}^{*}$ & - \\
\hline C & $63.04 \pm 0.70$ & $-3.08 \pm 0.40$ & $34.44 \pm 0.66$ & 3.54 \\
\hline S4DY1 & $61.68 \pm 0.64$ & $-2.34 \pm 0.46$ & $31.25 \pm 0.43$ & 4.14 \\
\hline S5DY1 & $61.16 \pm 0.76$ & $-2.07 \pm 0.50$ & $30.89 \pm 0.55$ & 4.01 \\
\hline S6DY1 & $61.26 \pm 0.76$ & $-2.05 \pm 0.43$ & $30.99 \pm 0.49$ & 4.33 \\
\hline S4DY2 & $62.68 \pm 0.55$ & $-3.07 \pm 0.57$ & $30.12 \pm 0.69$ & 2.92 \\
\hline S5DY2 & $62.62 \pm 0.61$ & $-2.78 \pm 0.45$ & $31.56 \pm 0.64$ & 4.93 \\
\hline S6DY2 & $62.29 \pm 0.72$ & $-2.60 \pm 0.60$ & $29.59 \pm 0.55$ & \\
\hline
\end{tabular}

* Average values and standard deviations

$\mathrm{L}^{*}$ values, showing a darker crust, than that with rice flour. In both cases, soy incorporation decreased the $\mathrm{L}^{*}$ value because of the flour color. Higher maize and soy flour levels in the formulation produced bread with higher $a^{*}$ and $b^{*}$ values because of the characteristic color of these flours.

Phimolsiripol, Mukprasirt, and Schoenlechner (2012) studied the influence of the addition of rice bran to rice-based gluten-free bread and the effect of egg albumin, emulsifiers and hydroxypropyl methylcellulose (HPMC) on gluten-free bread quality. The results showed that egg albumen produced significant effects on $\mathrm{L}^{*}$ and $\mathrm{a}^{*}$ values, but not on $b^{*}$ values of crust color.

In order to determine whether the color differences between the control and bread samples with soy flour could be detectable by the human eye $(\Delta \mathrm{E}>3)$, the parameter $\Delta \mathrm{E}$ was calculated (Table 2). It was found that the color differences between all analysed bread samples were obvious to the eye $(\Delta E>3)$ except the bread sample with $50 \%$ of soy flour and DY 252 (S5DY2), for which $1<\Delta \mathrm{E}<3$. Compared to the control, the crumb color of bread samples with soy flour was paler and had lost its yellow shades, which might be explained with the addition of eggs to the control bread formulation. Color differences among the bread slices are shown in Figure 5.

Ozola, Straumite, and Galoburda (2012) conducted a similar study on color differences among different types of muffins, namely, on the influence of various liquids used in recipes on the quality of gluten-free muffins. Regarding the color of crust, $\Delta \mathrm{E}$ revealed that color differences among all types of muffins were obvious $(\Delta E>3)$ to the human eye. The crust of muffins with milk had a dark brown color, but muffins with a milk-and-water mix had a pale yellow color. By contrast, the differences in crumb color among muffins with milk and with a milk-and- water mix and muffins with water and with a milkand-water mix were not obvious to the human eye $(\Delta \mathrm{E}<1)$.

\section{Conclusions}

The samples with DY 196 produced the best results of dough rheological properties, whereas the samples with DY 252 had the best quality of bread. The dough samples (DY 252) with a batterlike consistency proved to be the most appropriate for good-quality gluten-free bread production. Soy flour influenced the gluten-free dough rheological properties by improving (i.e., decreasing) dough firmness and resilience as well as moisture content in the dough samples with DY 252 compared to the control and dough samples with DY 196. Moreover, soy flour improved the volume, texture, hardness, moisture content and color of yellow maize-amaranth gluten-free bread.

Bread samples with DY 252 had good texture and specific volume and were softer than the control and samples with DY 196, which were significantly $(p<0.05)$ harder than the control sample. The addition of soy flour affected the color of gluten-free bread: Compared to the control, the crumb color of bread samples with soy flour was paler and had lost its yellow shades. No significant differences in the influence of soy flour on dough rheological properties and bread quality were found $(p>0.05)$ between the samples with various added amounts of soy flour $(45 \%, 50 \%$, or $60 \%)$.

\section{References}

1. Abdel-Aal, E.-S.M. (2009). Functionality of starch and hydrocolloids in gluten-free foods. In E. Gallagher (Ed.), Gluten-free Food Science and Technology (pp. 200-224). United Kingdom: John Wiley \& Sons. 
2. Alvarez-Jubete, L., Auty, M., \& Arendt, E.K. (2010). Baking properties and microstructure of pseudocereal flours in gluten-free bread formulations. European Food Research and Technology, 230, 437-445. DOI: 10.1007/ s00217-009-1184-z.

3. Anton, A.A., \& Artfield, S.D. (2008). Hydrocolloids in gluten-free breads: A review. International Journal of Food Science and Nutrition, 59(1), 11-23. DOI: 10.1080/09637480701625630.

4. Arendt, E.K., \& Nunes, M.H.B. (2010). Processing gluten-free foods. In J.I. Boye \& S.B. Godefroy (Eds.), Allergen Management in the Food Industry (pp. 333-354). New Jersey: John Wiley \& Sons.

5. Ballabio, C., Uberti, F., Di Lorenzo, C., Brandolini, A., Penas, E., \& Restani, P. (2011). Biochemical and immunochemical characterization of different varieties of amaranth (Amaranthus L. ssp.) as a safe ingredient for gluten-free products. Journal of Agriculture and Food Chemistry, 59(24), 12969-12974. DOI: 10.1021/jf2041824.

6. Blanco, C.A., Ronda, F., Perezs, B., \& Pando, V. (2011). Improving gluten-free bread quality by enrichment with acidic food additives. Food Chemistry, 127, 1204-1209. DOI: 10.1016/j.foodchem.2011.01.127.

7. Catassi, C., \& Fasano, A. (2008). Celiac disease. Current Opinion in Gastroenterology, 24(6), 687-691. DOI: 10.1097/MOG.0b013e32830 edcle.

8. Crockett, R., Ie, P., \& Vodovotz, Y. (2011). Effects of soy protein isolate and egg white solids on the physicochemical properties of gluten-free bread. Food Chemistry, 129, 84-91. DOI: 10.1016/j.foodchem.2001.04.030.

9. Curic, D., Novotni, D., Tusak, D., Bauman, I., \& Gabric, D. (2007). Glutenfree bread production by the corn meal and soybean flour extruded blend usage. Agriculture Conspectus Scientificus, 72(3), 227-232.

10. Czuchajowska, Z., Pomeranz, Y., \& Jetters H.C. (1988). Water activity and moisture content of dough and bread. Cereal Chemistry, 66(2), 128-132.

11. Decock, P., \& Cappelle, S. (2005). Bread technology and sourdough technology. Trends in Food Science \& Technology. 16, 113-120. DOI: $10.1016 /$ j.tifs.2004.04.012

12. Demirkesen, I., Mert, B., Sumnu, G., \& Sahin, S. (2010a). Rheological properties of gluten-free bread formulation. Journal of Food Engineering, 96, 295-303. DOI: 10.1016./j. jfoodeng.2009.08.004.

13. Demirkesen, I., Mert, B., Sumnu, G., \& Sahin, S. (2010b). Utilization of chestnut flour in gluten-free bread formulation. Journal of Food Engineering, 101, 329-336. DOI: 10.1016./j.jfoodeng.2010.07.017.

14. Esteller, M.S., \& Lannes S.C.S. (2008). Production and characterization of spongedough bread using scalded rye. Journal of Texture Studies, 39, 59-67. DOI: 10.1111/j.1745-4603.2007.00130.x.

15. EU Commission Regulation (EC) No 41/2009. (2009, January 20). Concerning the composition and labelling of foodstuffs suitable for people intolerant to gluten. Retrieved from http://eurlex.europa.eu/Lex UriServ/LexUriServ.do?uri=OJ:L:2009:016:000 3:0005:EN:PDF

16. Gallagher, E., Gormley, T.R., \& Arendt, E.K. (2003). Crust and crumb characteristics of gluten free breads. Journal of Food Engineering, 56, 153-161. DOI: 10.1016/S02608774(02)00244-3.

17. Gallagher, E., Gormley, T.R., \& Arendt, E.K. (2004). Recent advances in the formulation of gluten-free cereal-based products. Trends in Food Science \& Technology, 15, 143-152. DOI: 10.1016/j.tifs.2003.09.012.

18. Gobbetti, M., Rizzello, C.G., Di Cagno, R., \& De Angelis, M. (2007). Sourdough lactobacilli and celiac disease. Food Microbiology, 27, 187-196. DOI: 10.1016/j.fm.2006.07.014.

19. Heap, G.A., \& van Heel, D.A. (2009). Genetics and pathogenetics of coelic disease. Seminars in Immunology, 21, 346-354. DOI: 10.1016/j. smim.2009.04.001.

20. Lazaridou, A., Duta, D., Papageorgiou, M., Belc, N., \& Biliaderis, C.G. (2007). Effects of hydrocolloids on dough rheology and bread quality parameters in gluten-free formulation. Journal of Food Engineering. 79, 1033-1047. DOI: 10.1016./j.jfoodeng.2006.03.032.

21. Lopez, A.C.B., Pereira, A.J.G., \& Junqueira, R.G. (2004). Flour mixture of rice flour, corn and cassava starch in production of gluten-free white bread. Brazilian Archives of Biology and Technology, 47(1), 63-70. DOI: 10.1590/S1516-89132004000100009.

22. Marco, C., \& Rosell, C.M. (2008). Effect of different protein isolates and transglutaminase on rice flour properties. Journal of Food 
Engineering, 84, 132-139. DOI: 10.1016./j. jfoodeng.2007.05.003.

23. Mariotti, M., Lucisano, M., Pagani, M.A., \& Ng, P.K.W. (2009). The role of corn starch, amaranth flour, pea isolate, and Psyllium flour on the rheological properties and the ultrastructure of gluten-free doughs. Food Research International, 42, 963-975. DOI: 10.1016/j.foodres.2009.04.017.

24. Milde, L.B., Ramallo, L.A., \& Puppo, M.C. (2012) Gluten-free bread based on tapioca starch: texture and sensory studies. Food and Bioprocess Technology, 5(3), 888-896. DOI: $10.1007 / \mathrm{s} 11947-010-0381-x$.

25. Oates, C.G. (2001). Bread microstructure. In P. Chinachoti \& Y. Vodovotz (Eds.), Bread Staling (pp. 149-162). Boca Raton, Florida: CRC Press.

26. Onyango, C., Mutungi, C., Unbehend, G., \& Lindhauer, M.G. (2011). Modification of gluten-free sorghum batter and bread using maize, potato, cassava or rice starch. $L W T-$ Food Science and Technology, 44, 681-686. DOI: 10.1016./j.lwt.2010.09.006.

27. Ozola, L., Straumite, E., \& Galoburda, R. (2012). Quality of gluten-free muffins. Chemical Technology, 61, (3), 27-31. DOI: 10.5755/j01.ct.61.3.2716.

28. Ozola, L., Straumite, E., Galoburda, R., \& Klava, D. (2012). Application of extruded maize flour in gluten-free bread formulations. World Academy of Science, Engineering and Technology, 64, 883-888.

29. Ozola, L., Straumite, E., \& Klava, D. (2011). Extruded maize flour effect on the quality of gluten-free bread. In: Conference Proceedings of $6^{\text {th }}$ Baltic Conference on Food Science and Technology "Innovations for food science and production" - FOODBALT 2011, 5-6 May 2011 (pp. 131-136). Latvia, Jelgava: Latvia University of Agriculture, Faculty of Food Technology.

30. Peressini, D., Pin, M., \& Sensidoni, A. (2011). Rheology and breadmaking performance of rice-buckwheat batters supplemented with hydrocolloids. Food hydrocolloids, 25, 340-349. DOI: 10.1016./j.foodhyd.2010.06.012.
31. Phimolsiripol, Y., Mukprasirt, A., \& Schoenlechner, R. (2012). Quality improvement of rice-based gluten-free bread using different dietary fibre fractions of rice bran. Journal of Cereal Science, 56, 389-395. DOI: 10.1016/j.jcs.2012.06.001.

32. Renzetti, S., Dal Bello, F., \& Arendt, E.K. (2008). Microstructure, fundamental rheology and baking characteristics of batters and bread from different gluten-free fluors treated with a microbial transglutaminase. Journal of Cereal Science, 48, 33-45. DOI: 10.1016/j.jcs.2007.07.011.

33. Sana, M., Xhabiri, G., Seferi, E., \& Sinani, A. (2012). Influence of soy flour in baked products. Albanian Journal of Agricultural Sciences, 11(4), 255-259.

34. Sanz, T., Salvador, A., Baixauli, R., \& Fiszman, S.M. (2009). Evaluation of flour of resistant starch in muffins. II. Effects in texture, colour and consumer response. European Food Research and Technology, 229, 197-204. DOI: 10.1007/s00217-009-1040-1.

35. Sciarini, L.S., Ribotta, R.D., Leon, A.E., \& Perez, G.T. (2010). Influence of gluten-free flour and their mixtures on batter properties and bread quality. Food and Bioprocess Technology, 3, 577-585. DOI: 10.1007/s11947008-0098-2.

36. Sim, J., \& Tam, N. (2001). Eating qualities of muffins prepared with $10 \%$ and $20 \%$ soy flour. Journal of Nutrition in Recipe \& Menu Development, 3(4), 25-34. DOI: 10.1300/J071v03n02_03.

37. Torbica, A., Hadnadev, M., \& Dapčevic, T. (2010). Rheological, textural and sensory properties of gluten-free bread formulations based on rice and buckwheat flour. Food Hydrocolloids, 24, 626-632. DOI: 10.1016./j.foodhyd.2010.03.004.

38. Ziobro, R., Korus, J., Witczak, M., \& Juszczak, L. (2012). Influence of modified starches on properties of gluten-free dough and bread. Part II: Quality and staling of gluten-free bread. Food Hydrocolloids, 29, 68-74. DOI: 10.1016./ j.foodhyd.2012.02.009.

\section{Acknowledgements}

Research for this publication has been supported by the framework of the ERAF project "Promotion of scientific activities of LLU”, contract No. 2010/0198/2DP/2.1.1.2.0/10/APIA/VIAA/020. 